\title{
РАЗВИТИЕ НАЛОГОВОГО ВЗАИМОДЕЙСТВИЯ КАК СПОСОБ ПОВЫШЕНИЯ РЕЙТИНГА ВСЕМИРНОГО БАНКА «DOING BUSINESS»
}

\begin{abstract}
Аннотация: Предмет исследования составляют финансовые отношения, складывающиеся при взаимодействии налоговых органов и налогоплательщиков. В статье проанализированы позиции Российской Федерации в рейтинге Всемирного Банка "Doing Business». Paссмотрена динамика таких индикаторов как "Налогообложение» и "Регистрация предприятий». Обосновано, что развитие налогового взаимодействия во многом влияет на положение в указанном рейтинге Всемирного банка. Представлены направления развития взаимодействия налоговых органов и налогоплательщиков. Исследованы акты законодательства, определяющие государственную налоговую политику в среднесрочной перспективе. Методологической основой исследования послужили законодательство Российской Федерации о налогах и сборов, статистические данные о рейтинге Всемирного банка "Doing Business». В работе применены методы анализа и синтеза, дедукции и индукции. Анализом основных направлений развития налогового взаимодействия обоснованно его влияние на рейтинг Всемирного Банка "Doing Business». Повышение качества, ускорение и упрощение налоговых процедур; совершенствование налогового учета и отчетности; устранение неопределенности, пробелов и внутренних противоречий налогового законодательства; создание возможностей для подачи заявлений, обращений, запросов и документов на государственную регистрацию онлайн; обеспечение доступа к информации о: состоянии расчетов с бюджетами; законодательстве о налогах и сборах; ходе процедур налогового взаимодействия имеют решающее значение для инвестирования капитала и развития частного бизнеса.
\end{abstract}

Ключевые слова: Doing Business, рейтинг, политика, администрирование, взаимодействие, налоговые органы, налогоплательщики, Всемирный банк, индикаторы, динамика.

T1 овышение доходов бюджетной системы, прежде всего за счет улучшения администрирования уже существующих налогов, а также путем оптимизации налогообложения в целях стимулирования и расширения предпринимательской деятельности, в первую очередь, инновационной направленности является одним из важных направлений современной налоговой политики России.

Администрирование налоговых платежей должно осуществляться на основе минимизации издержек для экономических субъектов, что, по нашему мнению, может выражаться в развитии налогового взаимодействия бизнеса и государства (рис. 1).
Развитие взаимодействия налоговых органов и налогоплательщиков должно осуществляться в следующих направлениях: 1) повышение качества, ускорение и упрощение налоговых процедур, включая процедуру уплаты и возмещения излишне уплаченных (взысканных) налогов; 2) совершенствование налогового учета и отчетности; 3) устранение неопределенности, пробелов и внутренних противоречий налогового законодательства; 4) создание возможностей для подачи документов на государственную регистрацию онлайн; 5) создание возможностей для подачи заявлений, обращений, запросов онлайн; 6) обеспечение доступа к информации о: состоянии расчетов с бюджетами; законода- 
DOI: $10.7256 / 1812-8688.2014 .6 .12196$

При цитировании этой статьи сноска на doi обязательна

Налоговое администрирование

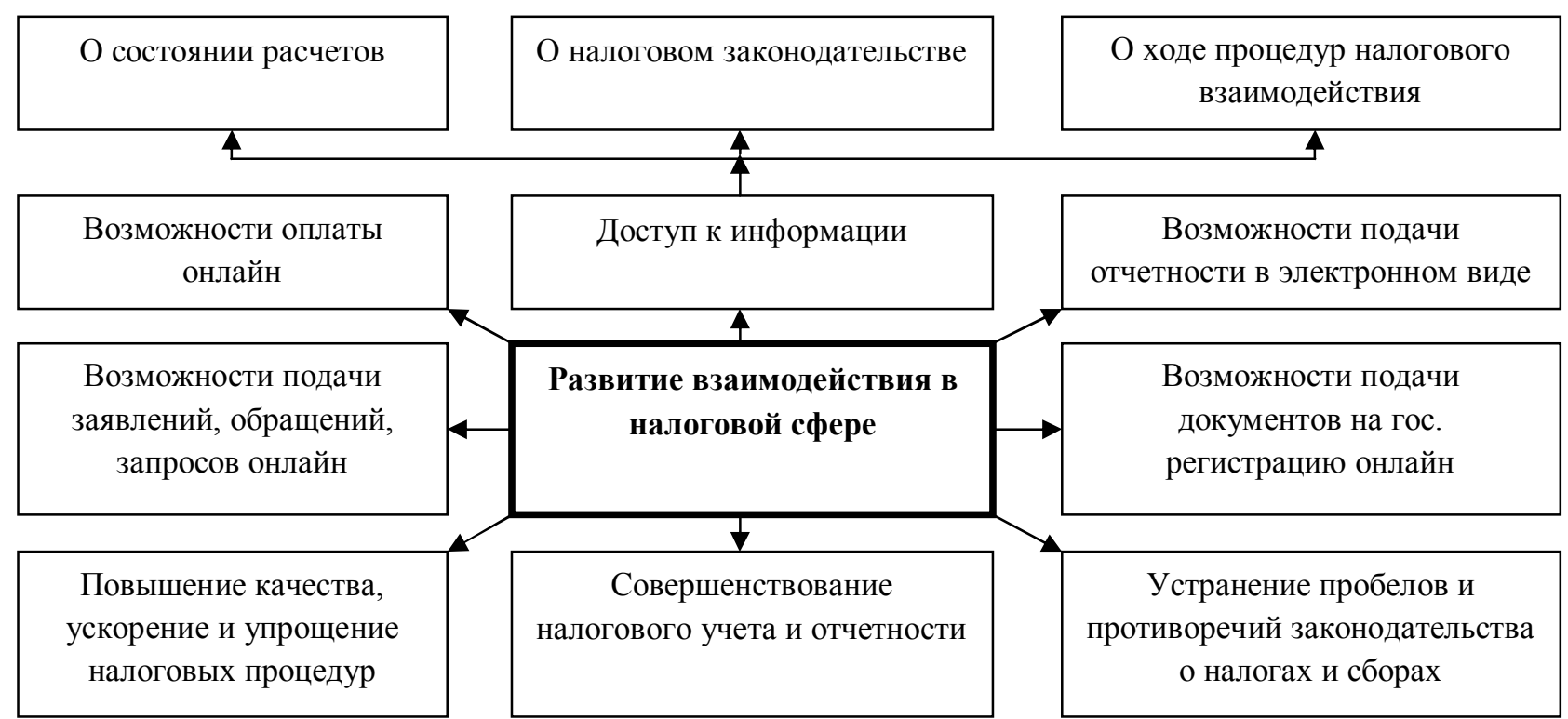

Рисунок 1 - Направления развития взаимодействия налоговых органов и налогоплательщиков. (Составлено автором)

тельстве о налогах и сборах; ходе процедур налогового взаимодействия, что должно обеспечивать устойчивое формирование бюджетных доходов, необходимых для исполнения расходных обязательств Российской Федерации, субъектов Российской Федерации и муниципальных образований.

Непосредственными результатами развития налогового взаимодействия являются: уменьшение количества судебных исков со стороны налогоплательщиков; улучшение разъяснительной работы по применению законодательства о налогах и сборах; расширение сферы предоставляемых информационных услуг гражданам и юридическим лицам.

Развитие налогового взаимодействия во многом определяет рейтинг Всемирного банка «Ведение бизнеса» (Doing Business), где страны ранжируются по благоприятствию ведения бизнеса с 1 до 189 места, первое место - наиболее высокое.

Рейтинг Всемирного банка является важной составляющей российской экономики. Группа Всемирного банка может предоставлять развивающимся странам займы по низким ставкам, беспроцентные кредиты и гранты, помогая им решать стоящие перед ними задачи в самых разных областях деятельности, таких как образование, здравоохранение, государственное управление, инфраструктура, развитие финансового и частного секторов, сельское хозяйство, охрана окружающей среды и управление природными ресурсами.

Высокая позиция в индексе легкости ведения бизнеса означает, что регуляторный климат благоприятствует ведению бизнеса. Индекс является средним показателей страны по 10 индикаторам (регистрация предприятий; получение разрешений на строительство; подключение к системе электроснабжения; кредитование; защита инвесторов; налогообложение; международная торговля; обеспечение исполнения контрактов; разрешение неплатежеспособности), каждый индикатор имеет равный вес ${ }^{1}$.

1 Рейтинг экономик. URL: http://russian.doingbusiness. org/Rankings. 
Начиная с 2011 года, Федеральная налоговая служба России ведет активное сотрудничество с Всемирным банком, направленное на обеспечение прозрачности и упрощения процедур взаимодействия налогоплательщиков с налоговыми органами.

Благодаря развитию бесконтактных способов взаимодействия с налоговыми органами, в том числе при осуществлении процедуры государственной регистрации юридических лиц и индивидуальных предпринимателей, упрощению отдельных процедур, связанных с взиманием НДС, и внедрению процедур досудебного урегулирования споров, в обновленном рейтинге Всемирного банка «Ведение бизнеса 2013» (Doing Business 2013 по итогам 2011 года) Российская Федерация:

- по индикатору «Создание компании» (Starting a Business 2013) поднялась на 4 позиции (со 105 до 101)

- по индикатору «Уплата налогов» (Paying Taxes 2013) поднялась на 30 позиций (с 94 до 64) ${ }^{2}$.

В целом Российская Федерация в отчете Doing Business 2014 по итогам 2012 года, поднялась за год в списке с 112 до 92 позиции (табл. 1).

Индикатор «Налогообложение» предоставляет информацию о налогах, которые должна уплатить в определенном году компания среднего размера, а также сопоставляет административную нагрузку, связанную с уплатой налогов.

По агрегированному значению индикатора «Налогообложение» за 2012 год Российская Федерация заняла 56 место в рейтинге. По данному показателю Российская

\footnotetext{
2 О результатах и основных направлениях деятельности Федеральной налоговой службы на 2014-2016 годы. URL: http://www.nalog.ru/rn34/related activities/ statistics_and_analytics/effectiveness.
}

Федерация опережает среднее значение по странам БРИКС (124 место), странам «Большой двадцатки» (84 место), странам ОЭСР (в среднем - 59 место) (табл. 2).

Среди стран «Группы 20» только у 7 стран более высокий индивидуальный страновой рейтинг по индикатору «Налогообложение», из них 5 являются членами ОЭСР: Австралия (44 место), Великобритания (14 место), Канада (8 место), Франция (52 место), Южная Корея (25 место), а также Саудовская Аравия (3 место) и ЮАР (24 место).

Основным конкурентным преимуществом этих стран по сравнению с Российской Федерацией является более низкая налоговая нагрузка на компании, преимущественно в части налогов на фонд оплаты труда и прочих налогов.

До определенного момента рейтинг Российской Федерации находился под давлением системы налогообложением имущества организаций. Это было связано, в первую очередь, с тем, что в большинстве стран ОЭСР активная часть производственных фондов освобождается от имущественного налогообложения.

В качестве мер, повлиявших на повышение позиции России в рейтинге Doing Business, можно выделить такие, как:?

- отмена с 2013 года налога на имущество организаций в отношении вновь вводимого движимого имущества, которое по экспертным оценкам составляет около половины балансовой стоимости основных средств;

- снижение в 2012 году тарифов страховых взносов до 30 \% с 34 \% в 2011 году. В целях упрощения, удешевления и ускорения действующих на территории Российской Федерации процедур по ведению бизнеса Правительством Российской Федерации утвержден ряд дорожных карт, разра- 
Динамика рейтинга «Doing Business» в России в 2006-2012 гг.

\begin{tabular}{|c|c|c|c|c|c|c|c|}
\hline $\begin{array}{c}\text { Оцениваемый год / } \\
\text { Наименование } \\
\text { отчета }\end{array}$ & 2006 г. & 2007 г. & 2008 г. & 2009 г. & 2010 r. & 2011 г. & 2012 г. \\
\hline & DB 2008 & DB 2009 & DB 2010 & DB 2011 & DB 2012 & DB 2013 & DB 2014 \\
\hline $\begin{array}{l}\text { Позиция России } \\
\text { в общем рейтинге } \\
\text { «Ведение бизнеса» }\end{array}$ & 106 & 120 & 116 & 124 & 118 & 111 & 92 \\
\hline \multicolumn{8}{|l|}{ В Т.ч. } \\
\hline $\begin{array}{l}\text { «Налогообло } \\
\text { жение» }\end{array}$ & 130 & 134 & 103 & 107 & 94 & 63 & 56 \\
\hline $\begin{array}{l}\text { «Регистрация пред- } \\
\text { приятий» }\end{array}$ & н.Д. & н.Д. & н.д. & 106 & 111 & 100 & 88 \\
\hline
\end{tabular}

Источник: Проект основных направлений налоговой политики Российской Федерации на 2015 год и на плановый период 2016 и 2017 годов. URL: http://www.minfin.ru/ru.

Таблица 2.

\section{Значение индикатора «Налогообложение» рейтинга «Ведение бизнеса» за 2012 год}

\begin{tabular}{|l|c|c|c|c|}
\hline \multicolumn{1}{|c|}{ Индикатор } & $\begin{array}{c}\text { Страны } \\
\text { ОЭСР } \\
\text { (среднее) }\end{array}$ & $\begin{array}{c}\text { Страны G20 } \\
\text { (среднее, } \\
\text { кроме России) }\end{array}$ & $\begin{array}{c}\text { Страны БРИКС } \\
\text { (среднее, } \\
\text { кроме России) }\end{array}$ & Россия \\
\hline Рейтинг & 59 & 84 & 124 & 56 \\
\hline Выплаты (количество) & 12 & 13 & 18 & 7 \\
\hline Время (часы) & 184 & 218 & 251 & 177 \\
\hline Налог на прибыль (\% прибыли) & 16,3 & 17,7 & 20,4 & 8 \\
\hline $\begin{array}{l}\text { Налог и выплаты на зарплату } \\
\text { (\% прибыли) }\end{array}$ & 23,5 & 23,1 & 26,9 & 36,7 \\
\hline Другие налоги (\% прибыли) & 2,1 & 8,2 & 10,3 & 6,1 \\
\hline $\begin{array}{l}\text { Общая налоговая ставка } \\
\text { (\% прибыли) }\end{array}$ & 41,8 & 49,0 & 57,5 & 50,7 \\
\hline
\end{tabular}

Источник: Проект основных направлений налоговой политики Российской Федерации на 2015 год и на плановый период 2016 и 2017 годов. URL: http://www.minfin.ru/ru.

ботанных в рамках национальной предпринимательской инициативы по улучшению инвестиционного климата в России.

В частности, утвержден План мероприятий («дорожная карта») «Совершенствование налогового администрирования».
На основе указанной дорожной карты будет осуществляться дальнейшее совершенствование налогового администрирования и снижение налоговой нагрузки на бизнес в целях формирования благоприятных условий для ведения предпринимательской деятельности. 
Значение индикатора «Регистрация предприятий» рейтинга «Ведение бизнеса» за 2012 год

\begin{tabular}{|l|c|c|c|l|}
\hline \multicolumn{1}{|c|}{7 Индикатор } & $\begin{array}{c}\text { Страны ОЭсР } \\
\text { (среднее) }\end{array}$ & $\begin{array}{c}\text { Страны G20 } \\
\text { (среднее, } \\
\text { кроме России) }\end{array}$ & $\begin{array}{c}\text { Страны БРИКС } \\
\text { (среднее, кроме } \\
\text { России) }\end{array}$ & Россия \\
\hline Рейтинг & 61 & 85 & 131 & 88 \\
\hline Процедуры (количество) & 5 & 8 & 11 & 7 \\
\hline Срок (дни) & 11,1 & 20,6 & 46,6 & 15,0 \\
\hline $\begin{array}{l}\text { Стоимость (\% дохода } \\
\text { на душу населения) }\end{array}$ & 3,6 & 9,8 & 13,6 & 1,3 \\
\hline $\begin{array}{l}\text { Минимальный оплачен- } \\
\text { ный капитал (\% валового } \\
\text { дохода на душу населения) }\end{array}$ & 10,4 & 15,0 & 50,7 & 1,2 \\
\hline
\end{tabular}

Источник: Проект основных направлений налоговой политики Российской Федерации на 2015 год и на плановый период 2016 и 2017 годов. URL: http://www.minfin.ru/ru.

Таблица 4

Целевые показатели Плана мероприятий «Оптимизация процедур
регистрации юридических лиц и индивидуальных предпринимателей»

\begin{tabular}{|c|c|c|c|}
\hline $\begin{array}{c}\text { Наименование } \\
\text { показателя }\end{array}$ & $\begin{array}{c}\text { Текущее } \\
\text { значение }\end{array}$ & 2015 год & 2018 год \\
\hline $\begin{array}{l}\text { Позиция в рейтинге регистрации } \\
\text { юридических лиц }\end{array}$ & 111 & 60 & 20 \\
\hline количество этапов & 9 & 5 & 3 \\
\hline $\begin{array}{l}\text { Время на регистрацию юр. лица } \\
\text { (раб. дней) }\end{array}$ & 30 & 7 & 5 \\
\hline Стоимость регистрации юр. лица & 6100 & 4000 & 4000 \\
\hline
\end{tabular}

Источник: Распоряжение Правительства Российской Федерации от 07.03.2013 № 317-р.

Предусмотрены мероприятия, направленные на сокращение времени взаимодействия налогоплательщиков и налоговых органов, упрощение правил ведения учёта налогоплательщиками и оптимизацию принятия инвестиционных решений участниками рынка.

Реализация указанной «дорожной карты» должна привести к достижению Россией к 2015 году 50-го места в рейтинге «Ведение бизнеса» по показателю «Налогообложение».
Индикатор «Регистрация предприятий» предоставляет информацию о процедурах, которые должны быть соблюдены предпринимателем, приступающим к созданию промышленной или торговой компании, в соответствии с требованиями законодательства или общей практикой, а также сроки и затраты для их выполнения и минимальный размер уставного капитала.

По данному показателю Российская Федерация опережает среднее значение по странам БРИКС (131 место), уступая 
странам «Группы 20» (85 место) и странам ОЭСР (в среднем - 61 место) (табл. 3).

В целях дальнейшего продвижения в рассматриваемом рейтинге Всемирного банка предусмотрено выполнение Плана мероприятий «Оптимизация процедур регистрации юридических лиц и индивидуальных предпринимателей» (далее - План) утвержденного Распоряжением Правительства Российской Федерации от 07.03.2013 № 317-р (табл. 4).

Указанным Планом предусмотрены следующие меры:

- исключение необходимости свидетельствования подписи в нотариальном порядке в случае представления документов в регистрирующий орган лично заявителем (п. 4 Плана);

- введение права использовать типовые уставы, которые не потребуется представлять в регистрирующий орган (п. 2 Плана);

- отмена обязательности печати при прохождении процедур регистрации (п. 3 Плана);

- отмена обязанности налогоплательщика уведомлять налоговый орган об открытии счёта в банке (п. 11 Плана).

Реализация данных мер должна привести к уменьшению количества этапов, необходимых для регистрации юридических лиц и индивидуальных предпринимателей, а также к снижению количества времени и расходов, затрачиваемых на прохождение этих этапов. Это позволит России в 2015 году занять 60-е место, а к 2018 году подняться на 20-е место в рейтинге Doing Business по показателю «Регистрации юридических лиц».

Следует отметить, что в целевых индикаторах и показателях подпрограммы 4 «Обеспечение функционирования и развития налоговой системы Российской Федерации» государственной программы «Управление государственными финансами», утвержденной распоряжением Правительства Российской Федерации от 04.03.2013 № 293-р, так же заложены целевые индикаторы, обеспечивающие положительное влияние на рейтинг Всемирного банка «Doing Business» (табл. 5).

Важно отметить, что финансирование данной целевой подпрограммы осуществляется за счет федерального бюджета РФ (табл. 6).

Таки образом, можно сказать, что дальнейшая работа по развитию налогового администрирования должна положительно влиять на деятельность предприятий частного сектора, в особенности на малые и средние предприятия, способствовать проведению реформ и улучшению качества правил, лежащих в основе деятельности частного сектора.

Это важно, так как в условиях мировой экономики, которая характеризуется постоянными изменениями и трансформацией, определяющее значение имеет то, являются ли правила разумными или обременительными, создают ли они ошибочные стимулы или помогают в создании равных условий конкуренции, обеспечивают ли они прозрачность и стимулируют ли достижение достаточного уровня конкуренции.

Развитие налогового администрирования во многом влияет на положение России в рейтинге Всемерного банка «Doing Business», который является инструментом, позволяющим странам оценивать результаты, достигнутые в процессе построения благоприятной среды для предпринимательской деятельности, как в динамике по времени, так и по отношению друг к другу, и имеет решающее значение для инвестирования капитала. 
DOI: $10.7256 / 1812-8688.2014 .6 .12196$

При цитировании этой статьи сноска на doi обязательна

\section{Налоги и налогообложение - № 6(120) • 2014}

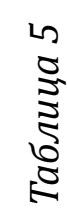

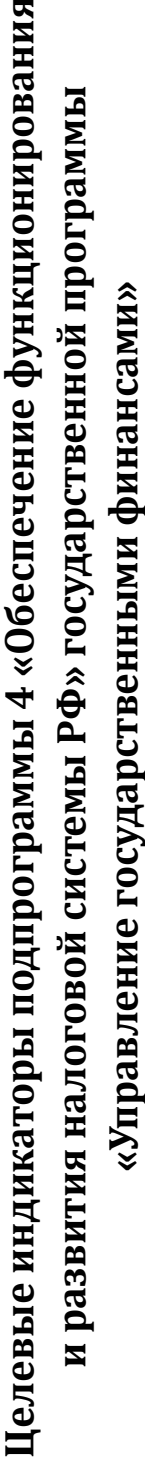

\begin{tabular}{|c|c|c|c|c|c|c|c|}
\hline $\begin{array}{l}\text { ్. } \\
\text { ঠి } \\
\text { N }\end{array}$ & $\begin{array}{l}0 \\
0 \\
\infty\end{array}$ & $\stackrel{\text { ㅇ }}{\underset{1}{\|}}$ & $\stackrel{\text { Ln }}{\underset{11}{\mathrm{~V}}}$ & $\vec{\sigma}^{-1}$ & 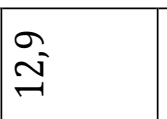 & $\tilde{m}_{0}^{m}$ & 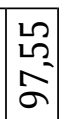 \\
\hline 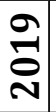 & 읏 & Ni & II & 훙 & 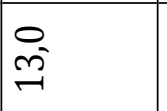 & mे & $\begin{array}{l}\text { 오 } \\
\text { á }\end{array}$ \\
\hline 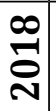 & 잉 & $\stackrel{\infty}{N}$ & III & 훙 & $\vec{m}$ & $\stackrel{\text { Ln }}{m}$ & $\begin{array}{l}\text { 오 } \\
\text { á }\end{array}$ \\
\hline 공 & $\begin{array}{l}0 \\
\text { เ్ }\end{array}$ & $\underset{\sim}{\pi}$ & $\underset{\mathrm{II}}{\stackrel{0}{\mathrm{I}}}$ & $\frac{7}{6}$ & $\tilde{m}^{n}$ & $\begin{array}{l}0 \\
\text { ma } \\
0\end{array}$ & $\begin{array}{l}\text { เภ } \\
\text { ล̊ }\end{array}$ \\
\hline $\begin{array}{l}0 \\
\stackrel{0}{0} \\
\text { N }\end{array}$ & ○े & 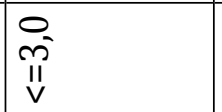 & 获 & $\begin{array}{l}0 \\
0 \\
0\end{array}$ & $\begin{array}{l}m \\
m \\
m\end{array}$ & $\hat{n}$ & $\begin{array}{l}\text { 영 } \\
\text { a }\end{array}$ \\
\hline 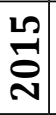 & 오 & $\stackrel{N}{\tilde{n}}$ & $\stackrel{\infty}{\stackrel{\infty}{\mathrm{V}}}$ & $\begin{array}{l}\sigma \\
\text { जo } \\
\text { - }\end{array}$ & $\stackrel{\vec{s}}{\stackrel{m}{\sim}}$ & $\begin{array}{l}\infty \\
\text { ñ } \\
0\end{array}$ & $\begin{array}{l}\text { L̊ } \\
\text { ลे }\end{array}$ \\
\hline 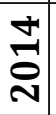 & $\stackrel{0}{0}$ & $\underset{⿱ ⺌}{\ddot{N}}$ & $\stackrel{\sigma}{\stackrel{a}{I I}}$ & $\begin{array}{l}\infty \\
\omega^{-}\end{array}$ & $\stackrel{\vec{\sigma}}{\stackrel{m}{\sim}}$ & ஜे & $\begin{array}{l}n \\
\sigma\end{array}$ \\
\hline 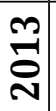 & $\begin{array}{l}0 \\
\infty \\
\infty \\
\text { Ln }\end{array}$ & 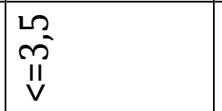 & $\begin{array}{l}\text { 음 } \\
\text { II } \\
v\end{array}$ & $\begin{array}{l}0 \\
150 \\
1\end{array}$ & $\begin{array}{l}\stackrel{2}{2} \\
\tilde{n}^{\prime}\end{array}$ & 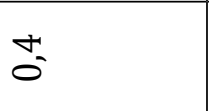 & $\begin{array}{l}N \\
\sigma\end{array}$ \\
\hline 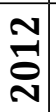 & $\begin{array}{l}0 \\
\bigcup^{\circ} \\
\text { เి }\end{array}$ & $\begin{array}{l}\infty \\
\stackrel{-}{11} \\
\mathbb{v}\end{array}$ & $\underset{v}{\mathbb{N}}$ & $\begin{array}{l}\text { 느 } \\
\text { Ln } \\
\end{array}$ & $\begin{array}{l}\overrightarrow{0} \\
\tilde{m}^{-}\end{array}$ & ㄴ? & ลે \\
\hline$\underset{\text { 겅 }}{\stackrel{-}{\circ}}$ & $\begin{array}{l}\text { Ln } \\
\text { เก }\end{array}$ & $\ddot{n}$ & $\begin{array}{l}0 \\
0 \\
0 \\
0\end{array}$ & $\stackrel{\overrightarrow{0}}{5}$ & ' & $\ddot{\sigma}$ & $\left|\begin{array}{l}n \\
0 \\
0 \\
-1\end{array}\right|$ \\
\hline 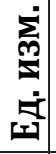 & $a^{0}$ & $\partial^{0}$ & $\partial^{0}$ & $a^{\circ}$ & $a^{0}$ & $a^{e}$ & $\partial^{\circ}$ \\
\hline 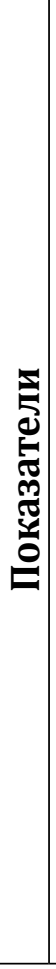 & 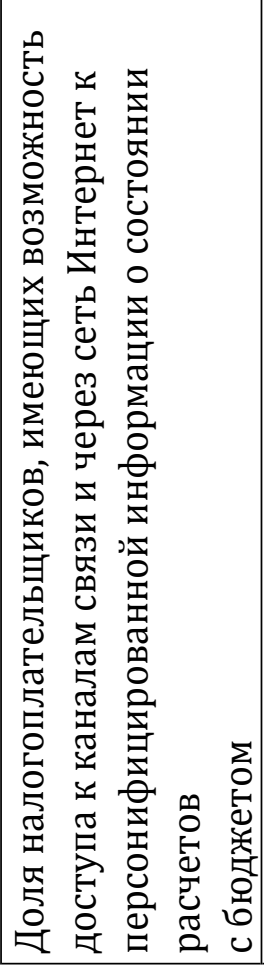 & 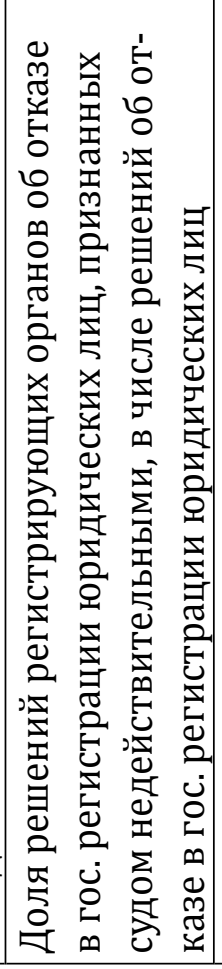 & 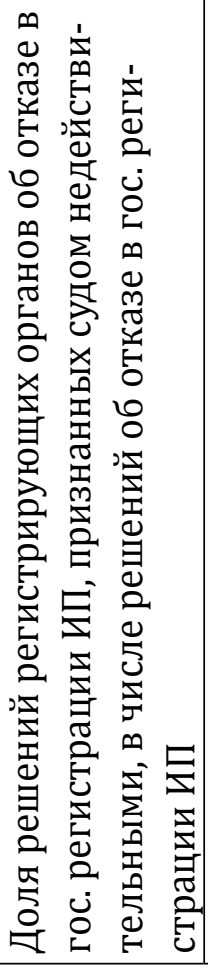 & 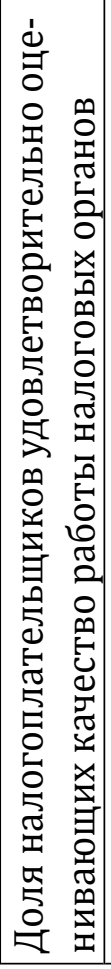 & 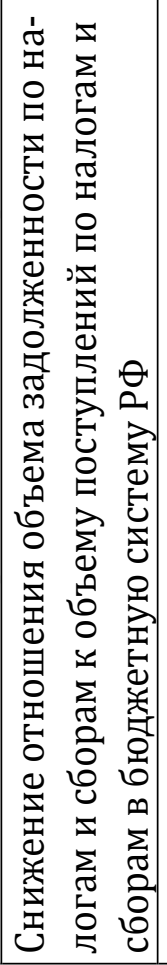 & 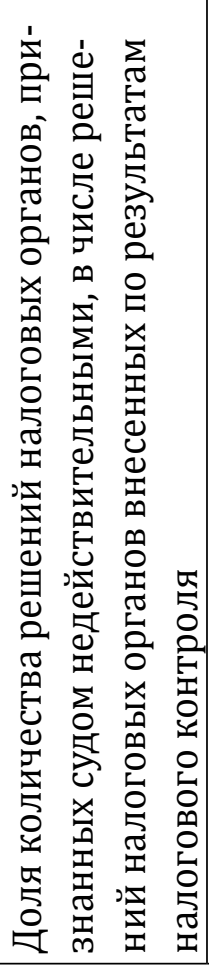 & $\mid \begin{array}{c}0 \\
0 \\
0 \\
0 \\
0 \\
0 \\
\vdots \\
0 \\
0 \\
0 \\
0 \\
0 \\
0 \\
0 \\
\mathbf{T} \\
0 \\
0 \\
0 \\
\vdots \\
0 \\
0 \\
0 \\
0 \\
0 \\
0 \\
0 \\
0\end{array}$ \\
\hline
\end{tabular}




\section{Финансирование подпрограммы 4 «Обеспечение функционирования и развития налоговой системы РФ» государственной программы «Управление государственными финансами» (руб.)}

\begin{tabular}{|c|c|c|}
\hline Год & Всего & Федеральный бюджет \\
\hline 2013 & 113515497,80 & 113515497,80 \\
\hline 2014 & 116830566,10 & 116830566,10 \\
\hline 2015 & 116227722,50 & 116227722,50 \\
\hline 2016 & 123816411,02 & 123816411,02 \\
\hline 2017 & 130561939,02 & 130561939,02 \\
\hline 2018 & 139088396,03 & 139088396,03 \\
\hline 2019 & 145422054,55 & 145422054,55 \\
\hline 2020 & 151963165,53 & 151963165,53 \\
\hline
\end{tabular}

Источник: Распоряжение Правительства Российской Федерации от 04.03.2013 № 293-р.

\section{Библиография:}

1. О результатах и основных направлениях деятельности Федеральной налоговой службы на 2014-2016 годы. URL: http://www.nalog.ru/rn34/related_activities/statistics_and_ analytics/effectiveness.

2. Проект основных направлений налоговой политики Российской Федерации на 2015 год и на плановый период 2016 и 2017 годов. URL: http://www.minfin.ru/ru.

3. Рейтинг экономик. URL: http://russian.doingbusiness.org/Rankings.

4. Распоряжение Правительства Российской Федерации от 07.03.2013 № 317-р «Об утверждении плана мероприятий («дорожной карты») «Оптимизация процедур регистрации юридических лиц и индивидуальных предпринимателей». Доступ из справочно-правовой системы «КонсультантПлюс».

5. Распоряжение Правительства Российской Федерации от 04.03.2013 № 293-р «Об утверждении государственной программы Российской Федерации «Управление государственными финансами». Доступ из справочно-правовой системы «КонсультантПлюс».

\section{References:}

1. O rezul'tatakh i osnovnykh napravleniyakh deyatel'nosti Federal'noi nalogovoi sluzhby na 2014-2016 gody. URL: http://www.nalog.ru/rn34/related_activities/statistics_and_ analytics/effectiveness.

2. Proekt osnovnykh napravlenii nalogovoi politiki Rossiiskoi Federatsii na 2015 god i na planovyi period 2016 i 2017 godov. URL: http://www.minfin.ru/ru.

3. Reiting ekonomik. URL: http://russian.doingbusiness.org/Rankings.

4. Rasporyazhenie Pravitel’stva Rossiiskoi Federatsii ot 07.03.2013 № 317-r «Ob utverzhdenii plana meropriyatii («dorozhnoi karty») «Optimizatsiya protsedur registratsii yuridicheskikh lits i individual'nykh predprinimatelei». Dostup iz spravochno-pravovoi sistemy «Konsul'tantPlyus».

5. Rasporyazhenie Pravitel'stva Rossiiskoi Federatsii ot 04.03.2013 № 293-r «Ob utverzhdenii gosudarstvennoi programmy Rossiiskoi Federatsii «Upravlenie gosudarstvennymi finansami». Dostup iz spravochno-pravovoi sistemy «Konsul'tantPlyus». 